A C G

Rec. Nat. Prod. 12:5 (2018) 445-459

records of natural

products

publications

\title{
Anatolian Propolis Prevents Oxalate Kidney Stones: Dramatic Reduction of Crystal Deposition in Ethylene-Glycol-Induced Rat Model
}

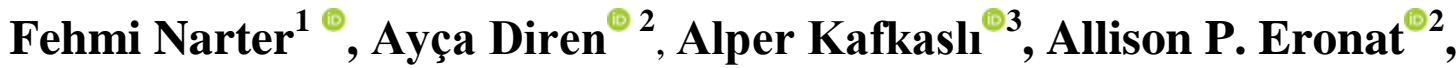 \\ M. Fatih Seyhan ${ }^{\oplus 2}$, Hülya Yılmaz-Aydoğan ${ }^{\oplus 2}$, Sukran Sarıkaya ${ }^{\oplus 4}$, \\ Seda Damla Hatipoğlu ${ }^{\oplus 5}$, Kemal Sarıca ${ }^{\oplus 1}$ and Oguz Ozturk $^{{ }^{\circledR *}}$
}

${ }^{1}$ Department of Urology, Kartal Dr.Lütfi Kırdar Research and Training Hospital, Istanbul, Türkiye

${ }^{2}$ Department of Molecular Medicine, Institute of Experimental Medicine, Istanbul University, Istanbul, Türkiye

${ }^{3}$ Department of Urology, Istanbul Yeni Yuzyil University, Istanbul, Türkiye

${ }^{4}$ Department of Pathology, Kartal Dr.Lütfi Kırdar Research and Training Hospital, Istanbul, Türkiye

${ }^{5}$ Reference Materials Laboratory, Chemistry Group, TUBITAK UME (National Metrology Institute),

Gebze-Kocaeli, Türkiye

(Received November 24, 2017; Revised January 16, 2018; Accepted January 20, 2018)

\begin{abstract}
One of the many properties of propolis, a gift of nature, is that it is a potent antioxidant agent, which has been shown to be a miracle-worker in many different diseases. In this study, its possible protective and reversing effects against hiperoxaluria was investigated in a rat model in comparison with verapamil. In all 5 groups (Total $n=76$ ), aside from the control, hiperoxaluria was induced with continuous ethylene glycol (EG) administration. The others received EG only, $50 \mathrm{mg} / \mathrm{kg}$ propolis, $100 \mathrm{mg} / \mathrm{kg}$ propolis and $1 \mathrm{mg} / \mathrm{kg}$ verapamil. To estimate the antioxidant/oxidant status in the tissue and serum samples, catalase (CAT), superoxide dismutase (SOD), total glutathione (GSH), nitric oxide (NO), malonyl dialdehyde (MDA) and total anti-oxidant capacity (T-AOC) were measured after 7 and 28 days. In the early phase, serum T-AOC levels were significantly elevated in the $\mathrm{EG}+\mathrm{P} 100(\mathrm{p}=0.0062)$ compared to the control, while in the late phase, it was elevated in the EG+P50 $(\mathrm{p}=0.037)$ and $\mathrm{EG}+\mathrm{V}(\mathrm{p}=0.009)$ compared to the $\mathrm{EG}$ only group. Propolis administration was observed to dramatically decrease crystal deposition $(\mathrm{p}<0.0001)$ and was more effective in the prevention of oxalate-induced renal injury than verapamil. Propolis being a natural product with almost none adverse effects elevates its value as a future approach to urolithiasis.
\end{abstract}

Keywords: Hyperoxaluria; propolis; verapamil; antioxidant; crystal deposition. (C) 2018 ACG Publications. All rights reserved.

\section{Introduction}

Propolis, a honey-bee product, is known to comprise the most powerful antioxidant agents. Over hundreds of compounds have been identified related to propolis. The main groups can be summarized

" Corresponding author: E Mail: dr.oguzozturk@gmail.com 
as phenolic acids, flavonoids, terpenes, lipid-wax substances, beeswax, bio-elements, essential oils and sugars [1-3]. Phenolic compounds, namely phenolic acids, phenolic aldehydes, phenols and their esters, ketophenols, coumarins, eugenol, anethole, hydroquinone, pterostilbene, naphthalene, etc., determines the quality and type of propolis [1] and especially flavonoids (caffeic acid phenethyl ester (CAPE), cinnamic acid etc.) are responsible for its biological activity [4,5]. The compounds that constitute propolis have attracted attention and recently studies have been conducted concerning its vasoprotective, anti-oxidant, anti-inflammatory, anti-cancer and anti-angiogenic features [6,7].

Although hyperoxaluria is common in the general population, there are no specific treatment approaches. Renal tubular epithelium is one of the major sites of oxalate- induced injury where sustained hyperoxaluria and subsequent calcium oxalate $(\mathrm{CaOx})$ crystal formation/deposition could be damaging to the renal tubular cells [8-11]. In the case of oxalate formation, increased reactive oxygen species (ROS) directly damage the renal cells, furthermore; obstruction of the urinary channels and the subsequent elevation of intrarenal tubular pressure is an indirect effect. This entity is recognized as crystal induced acute kidney injury. ROS effect tissues by impairing different pathways related to DNA damage and protein modifications. Moreover, increased ROS in some systematic diseases may also lead to kidney damage. The $\mathrm{CaOx}$ crystals and/or oxalate ions play a vital role in the formation of urinary calculi [12-14]. In order to understand the mechanism of cell damage during hyperoxaluria, stimulated lipid peroxidation in tubular cells, ROS and its formation causing oxidative stress should be evaluated all together. Hyperoxaluria-induced tubular ischemia may have a major role in initiating the programmed sequence of events leading to cell death $[15,16]$.

In this study, it was aimed to investigate the presence and extent of intratubular crystal formation along with the oxidant/antioxidant status in the kidney tissues and serum samples, and the conceivable protective effects of two agents, verapamil and propolis, on these changes induced by hyperoxaluria in a rat model. Moreover, the focus of this paper was to compile the setting inducing oxidative stress (OS) in kidneys and to perform a comparative analysis between verapamil and propolis in terms of their potential preventive affects on a urolithiasis model in rats.

\section{Materials and Methods}

\subsection{Animals}

A total of 76 female Sprague-Dawley rats (350-400 g each) were included to this study with the approval of the Ethical Committee of the Pendik Institute of Veterinary Control and Research (9414/013). All animals were kept in standard room conditions $\left(23 \pm 1{ }^{\circ} \mathrm{C}\right.$ and $55 \% \pm 5$ humidity) with day and night periods of 12 hours. Animals were then divided into four groups of treated animals and the untreated control group (Group 1) as early (7 days) and late (28 days) phase follow-up groups. In Group 2 (Ethylene Glycol (EG) only), hyperoxaluria was induced by administering animals $0.75 \%$ EG containing drinking water [17]. In addition to hyperoxaluria induction, animals in Group 3 were given propolis $(50 \mathrm{mg} / \mathrm{kg}$ through feeding tube); Group 4 were given high dose propolis (100 $\mathrm{mg} / \mathrm{kg}$ through feeding tube); and Group 5 were given verapamil ( $1 \mathrm{mg} / \mathrm{kg}$, through feeding tube). All groups were evaluated in early ( 7 days) and late (28 days) phases (Table 1$)$. Their daily water consumptions were similar.

Table 1. Study groups

\begin{tabular}{lccccc}
\hline Time & $\begin{array}{c}\text { Group 1 } \\
\text { Control } \\
(\mathbf{n})\end{array}$ & $\begin{array}{c}\text { Group 2 } \\
\text { EG } \\
(\mathbf{n})\end{array}$ & $\begin{array}{c}\text { Group 3 } \\
\text { EG+Propolis } \\
\mathbf{5 0}(\mathbf{n})\end{array}$ & $\begin{array}{c}\text { Group 4 } \\
\text { EG+Propolis } \\
\mathbf{1 0 0}(\mathbf{n})\end{array}$ & $\begin{array}{c}\text { Group 5 } \\
\text { EG+Verapamil } \\
(\mathbf{n})\end{array}$ \\
\hline $\begin{array}{l}\text { Early Phase } \\
\begin{array}{l}\text { (7 Days) } \\
\text { Late Phase } \\
(28 \text { Days) }\end{array}\end{array}$ & 6 & 8 & 8 & 8 & 8 \\
\hline
\end{tabular}

Following euthanasia via cervical dislocation, bilateral flank incisions were performed on the animals to remove both their kidneys for the histopathologic evaluation of crystal formation (under 
light microscopy) together with oxidant/antioxidant status in the tissue and serum samples by using the ELISA kits for catalase (CAT), superoxide dismutase (SOD), total glutathione (GSH), nitric oxide (NO), malonyl dialdehyde (MDA), total anti-oxidant capacity (T-AOC).

\subsection{Experimental Design}

Kidney tissue samples were collected following the cervical dislocation of the rats. Tissues were immersed in liquid nitrogen and pounded using a ceramic mortar and pestle. Then, they were homogenized using TissueRuptor ${ }^{\circledR}$ (Qiagen, Netherlands) and equilibrated to $1 \mathrm{mg}$ tissue $/ 1 \mathrm{ml}$ PBS (Phosphate Buffered Saline, Biochrome). Blood samples were acquired before euthanization and serum samples were separated for the ELISA tests.

\subsection{ELISA Tests}

The ELISA tests (YH-Biosearch, China) of catalase (CAT), superoxide dismutase (SOD), total glutathione (GSH), nitric oxide (NO), malonyl dialdehyde (MDA), and total anti-oxidant capacity (TAOC) were used to assess the oxidant/antioxidant status of the tissue and serum samples.

\subsection{Histological Analysis}

Evaluations of renal crystal deposition and calcification in tubules were performed under light microscopy for the late phase ( $28^{\text {th }}$ day) in order to appraise the utmost renal stone formation. Tissues were embedded in paraffin and stained with hematoxylin and eosin (HE) for histopathological evaluation. Detection of crystallization in the frozen sections of the kidneys of the rats treated only with $\mathrm{EG}$ or $\mathrm{EG}$ and propolis $(\mathrm{EG}+\mathrm{PRO})$ or $\mathrm{EG}$ and verapamil $(\mathrm{EG}+\mathrm{V})$, were qualitatively assessed by histopathological evaluation.

For each study group, crystal formations were calculated in a total of 240 renal tubules, forty tubules from 6 different microscopic fields.

\subsection{Preparation and Characterization of the Ethanolic Extract of Propolis}

Propolis was obtained from Altiparmak Inc. (Istanbul, Turkey). According to the validity and reliability tests performed by Altiparmak Inc. in Apilab Laboratories, the propolis sample was stated as suitable for consumption and no biological or heavy metal contamination were detected. It was dissolved in $70 \%(\mathrm{v} / \mathrm{v})$ ethanol and the final concentration was set as 30mg propolis/1g solution (w/w). The ethanolic extract was incubated overnight at $37 \mathrm{C}^{\circ}$ with occasional shaking and then filtered through a syringe filter ( 0.22 micron).

\subsection{Total Phenolic Contents and Total Antioxidant Activity Analysis (mg GAE/g)}

The total phenolic content (TPC) in propolis was determined using Folin-Ciocalteu reagent. The findings were demonstrated as $\mathrm{mg}$ gallic acid equivalent (GAE) $100 \mathrm{~g}^{-1}$ sample [18]. Total antioxidant capacity (TAC) was appraised using the 2,2-azinobis(3-ethylbenzothiazoline)-6-sulfonic acid (ABTS), 1,1-diphenyl-2-picrylhydrazyl (DPPH), ferric reducing antioxidant power (FRAP) and cupric ion reducing antioxidant capacity (CUPRAC) assays [19-22]. In all assays, 6-hydroxy-2,5,7,8tetramethylchroman-2-carboxylic acid (Trolox) was utilized as a standard and the findings were demonstrated as mg Trolox equivalent (TE) $100 \mathrm{~g}^{-1}$ sample.

Compounds and standards were purchased from Sigma-Aldrich, Merck, ExtraSynthese, Genay-France. LC-MS/MS analyses were performed using a Zivak ${ }^{\circledR}$ HPLC and Zivak ${ }^{\circledR}$ Tandem

Gold Triple Quadrupole (Istanbul, Turkey) mass spectrometer, equipped with a Synergy Max C18 column ( $250 \times 2 \mathrm{~mm}$ i.d., $5 \mu \mathrm{m}$ particle size) according to a previous study in Organic Chemistry 
Laboratory, Chemistry Group, National Metrology Institute, TUBITAK, Kocaeli, Türkiye [23] (Table 2 , Table 3 and supporting information).

Table 2. Phenolic contents of propolis sample by LC-MS/MS

\begin{tabular}{ll}
\multicolumn{1}{c}{ Phenolic Content } & \multicolumn{1}{c}{$(\mathbf{X} \pm$ SD) } \\
\hline Kaempferol & $1135.2 \pm 125.12$ \\
Fumaric acid & $4975.50 \pm 559.17$ \\
Pyrogallol & $5625.09 \pm 691.86$ \\
$p$-OH benzoic acid & $478.47 \pm 41.63$ \\
$p$-Coumaric acid & $4227.78 \pm 753.45$ \\
Caffeic acid & $7978.20 \pm 1598.88$ \\
$t$-Ferulic acid & $3121.84 \pm 289.92$ \\
Quercetin & $734.88 \pm 124.67$ \\
Ellagic acid & $52.08 \pm 4.62$ \\
Isorhamnetin & $571.95 \pm 76.46$ \\
Quercetagetin-3,6-dimethyl ether & $1819.86 \pm 378.14$ \\
Chlorogenic acid & $301.93 \pm 42.62$ \\
Rosmarinic acid & $139.36 \pm 14.10$ \\
Rutin & $1136.92 \pm 89.66$ \\
Gallic acid & $249.25 \pm 18.96$ \\
Salvigenin & $2597.53 \pm 227.36$ \\
Penduletin & $698.78 \pm 80.43$ \\
Total Phenolic Substance (mg GAE/g) & $143 \pm 15$ \\
\hline
\end{tabular}

$\mathrm{X}$ : Amount of substances as $\mathrm{mg} / \mathrm{kg}$

$\mathrm{SD}$ : Values are given as Mean $\pm \mathrm{SD}$

Table 3. Total antioxidant capacity of studied propolis sample

\begin{tabular}{cc}
\hline Applied Method & $(\mathbf{m g}$ TEAC/g)* \\
\hline ABTS & $207 \pm 36$ \\
CUPRAC & $575 \pm 31$ \\
DPPH & $151 \pm 33$ \\
FRAP & $140 \pm 18$ \\
\hline
\end{tabular}

*Values are given as Mean \pm SD

\subsection{Statistical Analysis}

The statistical analysis was performed using the GraphPad Prism 6.0 software. The data were analyzed by 2-way ANOVA test with Bonferroni method correction (alpha: 0.01) to find differences between the control and treated groups.

\section{Results and Discussion}

In this study, in the early period, serum MDA levels, a lipid peroxidation product, were similar among all groups compared to the control, while in the late period, a significant decrease was observed only in the EG+V group (Figure 1, Table 4). Conversely, several studies conducted on the possible preventive effects of various agents on urolithiasis showed higher tissue MDA levels following EG administration in rats $[24,25]$ and propolis has been demonstrated to decrease lipid peroxidation (MDA levels), as part of its antioxidant activity [26]. In this study, a slight decrease was observed in the EG+P100 group. This may be due to that the MDA test is not sufficient to determine oxidative stress. In fact, currently researches are debating over the reliability and efficiency of MDA testing in determining oxidative stress [27]. 

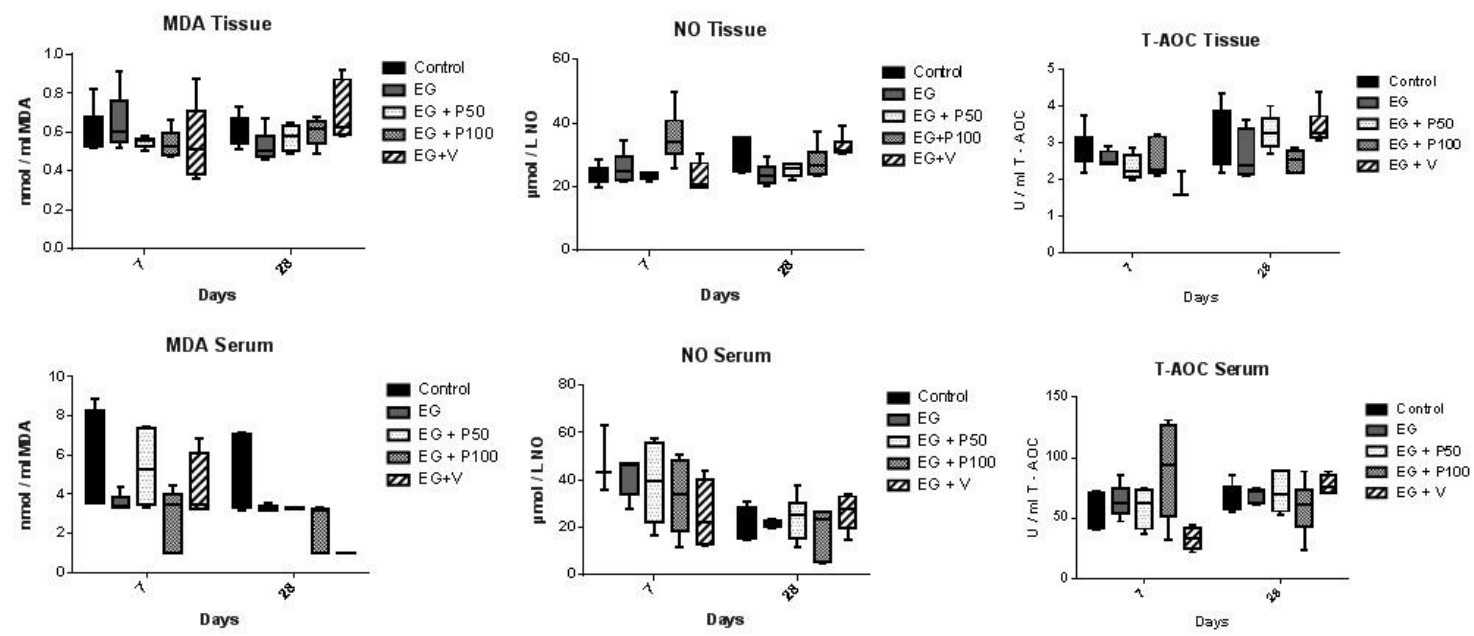

Figure 1. Serum and tissue levels of MDA, NO and T-AOC

In the early phase, serum NO levels were decreased in the EG+V group compared to both control and EG only groups. In the tissue samples, NO levels were elevated with propolis administration, yet reached significance in the EG+P100 group compared to the control group ( $\mathrm{p}=0.0001$, Figure 1, Table 5). Moreover, in the tissue samples compared to the EG only group, NO elevation was observed in EG+ P100 and decrease in the EG+V groups. In the late phase, NO levels seem unvaried aside from the elevation observed in the EG+V group when compared to the EG only group, indicating that Verapamil shows its efficiency in the long term. Since NO is a molecule metabolized shortly after its formation; our current findings indicate that the antioxidant systems eliminate it from the serum and tissue effectively until late phase as expected. One of the numerous benefits of propolis is its immune regulatory impact. Propolis has been shown to elevate NO levels [26], which is consistent with our findings.

Table 4. Estimation of the serum and tissue levels of MDA within the study groups

\begin{tabular}{clllcc}
\hline \multirow{2}{*}{ Days } & \multicolumn{2}{c}{ MDA } & \multicolumn{2}{c}{ SERUM } & \multicolumn{2}{c}{ TISSUE } \\
\cline { 3 - 6 } & & Mean \pm SD & P Value & Mean \pm SD & P Value \\
\hline \multirow{4}{*}{ Control } & $3.69 \pm 1.17$ & & $0.62 \pm 0.11$ & \\
& Control vs. EG & $4.02 \pm 0.44$ & 0.758 & $0.65 \pm 0.16$ & $>0.9999$ \\
& Control vs. EG+P50 & $5.38 \pm 0.84$ & 0.262 & $0.55 \pm 0.03$ & $>0.9999$ \\
& Control vs. EG + P100 & $2.68 \pm 0.71$ & 0.464 & $0.54 \pm 0.07$ & 0.9896 \\
& Control vs. EG + V & $4.26 \pm 0.88$ & 0.711 & $0.54 \pm 0.18$ & 0.8196 \\
& EG vs. EG+P50 & $5.383 \pm 2.06$ & 0.025 & $0.55 \pm 0.03$ & 0.3425 \\
& EG vs. EG + P100 & $2.814 \pm 1.46$ & 0.679 & $0.54 \pm 0.07$ & 0.2667 \\
& EG vs. EG + V & $4.046 \pm 1.40$ & $>0.9999$ & $0.54 \pm 0.18$ & 0.213 \\
& & & & & \\
\hline \multirow{4}{*}{28} & Control & $3.28 \pm 0.77$ & & $0.61 \pm 0.08$ & \\
& Control vs. EG & $3.34 \pm 0.04$ & 0.585 & $0.53 \pm 0.08$ & 0.8454 \\
& Control vs. EG+P50 & $3.02 \pm 0.29$ & 0.671 & $0.57 \pm 0.06$ & $>0.9999$ \\
& Control vs. EG + P100 & $3.71 \pm 0.96$ & 0.828 & $0.60 \pm 0.07$ & $>0.9999$ \\
& Control vs. EG + V & $0.99 \pm 0.01$ & $* * * *$ & $0.70 \pm 0.15$ & 0.581 \\
& EG vs. EG+P50 & $3.28 \pm 0.03$ & $>0.9999$ & $0.57 \pm 0.06$ & $>0.9999$ \\
& EG vs. EG + P100 & $2.49 \pm 1.16$ & 0.6067 & $0.60 \pm 0.07$ & 0.7826 \\
& EG vs. EG + V & $0.98 \pm 1.16$ & $0.0023 * *$ & $0.70 \pm 0.15$ & 0.0323 \\
\hline
\end{tabular}


Table 5. Estimation of serum and tissue levels of NO within the study groups

\begin{tabular}{llllll}
\hline \multirow{2}{*}{ Days } & \multicolumn{2}{c}{ NO } & \multicolumn{2}{c}{ SERUM } & \multicolumn{2}{c}{ TISSUE } \\
\cline { 3 - 6 } & Mean \pm SD & P Value & Mean \pm SD & P Value \\
\hline \multirow{4}{*}{ Control } & $45.49 \pm 9.11$ & & $23.85 \pm 3.08$ & \\
& Control vs. EG & $42.56 \pm 7.68$ & $>0.9999$ & $26.05 \pm 4.99$ & $>0.9999$ \\
& Control vs. EG+P50 & $39.2 \pm 15.29$ & $>0.9999$ & $23.33 \pm 1.07$ & $>0.9999$ \\
& Control vs. EG + P100 & $33.14 \pm 15.29$ & 0.1514 & $35.46 \pm 8.10$ & $0.0001 * * *$ \\
7 & Control vs. EG + V & $26.3 \pm 11.33$ & $0.0068 * *$ & $22.63 \pm 4.17$ & $>0.9999$ \\
& EG vs. EG+P50 & $39.2 \pm 15.29$ & $>0.9999$ & $23.33 \pm 1.07$ & 0.8944 \\
& EG vs. EG + P100 & $33.14 \pm 15.29$ & 0.3915 & $35.46 \pm 8.09$ & $0.0023 * *$ \\
& EG vs. EG + V & $26.3 \pm 11.33$ & $0.0331 * *$ & $22.63 \pm 4.16$ & 0.5773 \\
& & & & & \\
\hline \multirow{4}{*}{28} & Control & $21.56 \pm 5.36$ & & $29.65 \pm 4.98$ & \\
& Control vs. EG & $21.67 \pm 1.55$ & $>0.9999$ & $23.96 \pm 3.23$ & 0.1191 \\
& Control vs. EG+P50 & $24.20 \pm 9.09$ & $>0.9999$ & $25.29 \pm 2.00$ & 0.3709 \\
& Control vs. EG + P100 & $18.41 \pm 10.35$ & $>0.9999$ & $27.69 \pm 5.01$ & $>0.9999$ \\
& Control vs. EG + V & $26.97 \pm 6.85$ & $>0.9999$ & $32.55 \pm 3.39$ & $>0.9999$ \\
& EG vs. EG+P50 & $24.2 \pm 9.09$ & $>0.9999$ & $25.29 \pm 2.00$ & $>0.9999$ \\
& EG vs. EG + P100 & $18.41 \pm 10.34$ & $>0.9999$ & $27.69 \pm 5.01$ & 0.4684 \\
& EG vs. EG + V & $26.97 \pm 6.84$ & $>0.9999$ & $32.55 \pm 3.38$ & 0.0057 \\
\hline
\end{tabular}

In the early phase, serum and tissue T-AOC levels were elevated in the EG+P100 group, yet decreased in the $\mathrm{EG}+\mathrm{V}$ group, indicating that propolis is enhancing TAOC in the early period. In the late phase, when compared to EG only group $\mathrm{EG}+\mathrm{P} 50$ and $\mathrm{EG}+\mathrm{V}$ groups also supported $\mathrm{T}-\mathrm{AOC}$ ( $\mathrm{p}=$ 0.0062 , Table 6). The fact that T-AOC displays an additive impact of all antioxidant systems in the tissue, it may not be as specific as its constituents.

Table 6. Estimation of the serum and tissue levels of T-AOC within the study groups

\begin{tabular}{llllll}
\hline \multirow{2}{*}{ Days } & \multicolumn{1}{c}{ T-AOC } & \multicolumn{2}{c}{ SERUM } & \multicolumn{2}{c}{ TISSUE } \\
& \multicolumn{1}{c}{ Mean \pm SD } & P Value & Mean \pm SD & P Value \\
\hline \multirow{4}{*}{ Control } & $54.19 \pm 13.80$ & & $2.82 \pm 0.52$ & \\
& Control vs. EG & $63.74 \pm 13.16$ & $>0.9999$ & $2.57 \pm 0.19$ & $>0.9999$ \\
& Control vs. EG+P50 & $63.66 \pm 15.31$ & $>0.9999$ & $2.32 \pm 0.33$ & 0.3302 \\
& Control vs. EG + P100 & $89.00 \pm 40.54$ & $0.0062 * *$ & $2.54 \pm 0.50$ & $>0.9999$ \\
& Control vs. EG + V & $33.25 \pm 7.19$ & 0.1968 & $1.90 \pm 0.35$ & $0.0074 * *$ \\
& EG vs. EG+P50 & $63.66 \pm 15.31$ & $>0.9999$ & $2.32 \pm 0.33$ & 0.7023 \\
& EG vs. EG + P100 & $89 \pm 40.54$ & 0.082 & $2.53 \pm 0.50$ & 0.9992 \\
& EG vs. EG + V & $33.25 \pm 7.19$ & 0.0257 & $1.89 \pm 0.35$ & 0.0297 \\
& & & & & \\
\hline \multirow{4}{*}{28} & Control & $66.83 \pm 11.40$ & & $3.13 \pm 0.80$ & \\
& Control vs. EG & $68.90 \pm 5.73$ & $>0.9999$ & $2.65 \pm 0.64$ & 0.3857 \\
& Control vs. EG+P50 & $71.00 \pm 16.15$ & $>0.9999$ & $3.30 \pm 0.47$ & $>0.9999$ \\
& Control vs. EG + P100 & $58.42 \pm 21.44$ & $>0.9999$ & $2.51 \pm 0.28$ & 0.1362 \\
& Control vs. EG + V & $77.67 \pm 7.91$ & $>0.9999$ & $3.44 \pm 0.49$ & $>0.9999$ \\
& EG vs. EG+P50 & $71 \pm 16.14$ & $>0.9999$ & $3.298 \pm 0.47$ & 0.0376 \\
& EG vs. EG + P100 & $58.42 \pm 21.43$ & $>0.9999$ & $2.512 \pm 0.28$ & 0.9285 \\
& EG vs. EG + V & $77.67 \pm 7.90$ & $>0.9999$ & $3.435 \pm 0.49$ & $0.009 * *$ \\
\hline
\end{tabular}

Furthermore, propolis also has been shown to increase SOD and GPx owing to its antioxidant properties [26]. In this study, in the early period, only difference was observed in the EG+P50 group in 
terms of serum SOD levels compared to the control. In the late phase, compared to the EG only group, serum SOD levels were elevated, while tissue SOD levels were decreased in the EG+P50 and EG+V groups (Table 7, Figure 2). However, antioxidant administration such as green tea has been shown to elevate SOD levels in a similar model [28]. Serum GSH levels were decreased both in early $(p=0.005-$ $0.001)$ and late phases $(\mathrm{p}<0.0001)$ in all groups (Table 8$)$. In the early phase there was no difference observed in terms of serum or tissue CAT levels, while in the EG+V, EG+ P50 and EG+ P100 groups tissue CAT levels were decreased ( $\mathrm{p}=0.001$ Figure 2, Table 9).
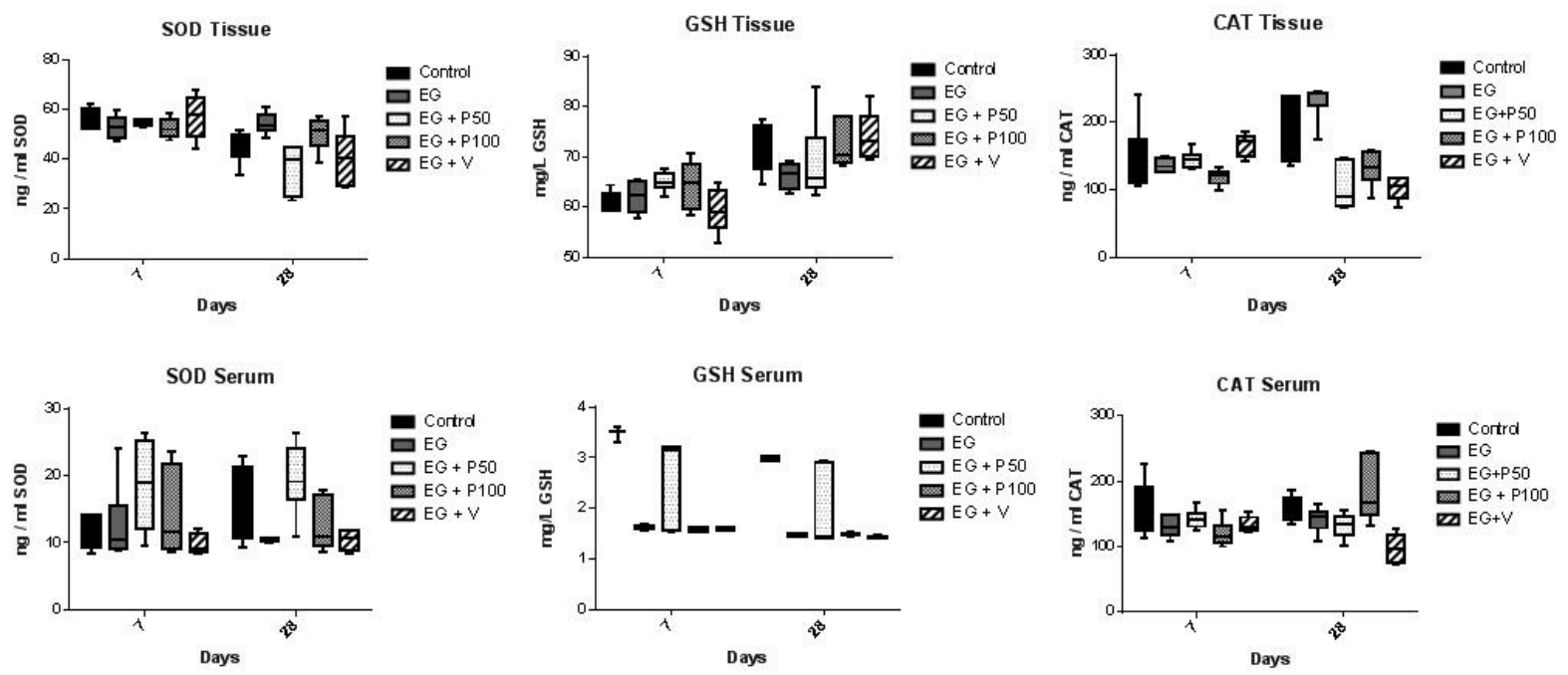

Figure 2. Serum and Tissue SOD, GSH and CAT levels.

Table 7. Estimation of the serum and tissue levels of SOD within study groups

\begin{tabular}{clllll}
\hline \multirow{2}{*}{ Days } & \multicolumn{1}{c}{ SOD } & \multicolumn{2}{c}{ SERUM } & \multicolumn{2}{c}{ TISSUE } \\
\cline { 3 - 6 } & Mean \pm SD & P Value & Mean \pm SD & P Value \\
\hline \multirow{4}{*}{ Control } & $11.41 \pm 2.26$ & & $54.95 \pm 4.30$ & \\
& Control vs. EG & $12.58 \pm 5.82$ & $>0.9999$ & $52.97 \pm 4.84$ & $>0.9999$ \\
& Control vs. EG+P50 & $18.55 \pm 7.51$ & 0.0406 & $54.59 \pm 1.34$ & $>0.9999$ \\
& Control vs. EG + P100 & $14.30 \pm 6.43$ & $>0.9999$ & $52.54 \pm 3.64$ & $>0.9999$ \\
7 & Control vs. EG + V & $9.76 \pm 1.43$ & $>0.9999$ & $57.31 \pm 7.94$ & $>0.9999$ \\
& EG vs. EG+P50 & $18.55 \pm 7.51$ & 0.1001 & $54.59 \pm 1.34$ & $>0.9999$ \\
& EG vs. EG + P100 & $14.3 \pm 6.43$ & $>0.9999$ & $52.54 \pm 3.64$ & $>0.9999$ \\
& EG vs. EG + V & $9.76 \pm 1.42$ & 0.9128 & $57.31 \pm 7.94$ & 0.7996 \\
& & & & & \\
\hline \multirow{4}{*}{ Control } & $15.48 \pm 5.74$ & & $45.15 \pm 6.40$ & \\
& Control vs. EG & $10.48 \pm 0.26$ & 0.2667 & $54.41 \pm 4.22$ & 0.0645 \\
Control vs. EG+P50 & $19.53 \pm 5.21$ & 0.5462 & $36.69 \pm 9.27$ & 0.1082 \\
Control vs. EG + P100 & $12.56 \pm 3.65$ & $>0.9999$ & $50.26 \pm 6.62$ & 0.7036 \\
Control vs. EG + V & $10.40 \pm 1.39$ & 0.2506 & $39.77 \pm 10.28$ & 0.6145 \\
& EG vs. EG+P50 & $19.53 \pm 5.21$ & $0.0055^{* *}$ & $36.69 \pm 9.27$ & $0.0001 * * *$ \\
& EG vs. EG + P100 & $12.56 \pm 3.65$ & $>0.9999$ & $50.26 \pm 6.62$ & 0.8596 \\
& EG vs. EG + V & $10.4 \pm 1.39$ & $>0.9999$ & $39.77 \pm 10.28$ & $0.0014 * *$ \\
\hline
\end{tabular}

Therefore, we suggest that tissue CAT may be used to eliminate oxidant effect delivered via EG administration in the late period $(\mathrm{p}<0.0001)$. However, in the late phase, when compared to the EG only group, this decrease seems to fade, while in the $\mathrm{EG}+\mathrm{V}$ group a significant elevation was 
observed. Thus, propolis was effective starting from the early phase but verapamil was effective in later periods (Figure 2).

Table 8. Estimation of serum and tissue levels of GSH within all groups

\begin{tabular}{llllll}
\hline \multirow{2}{*}{ Days } & \multicolumn{1}{c}{ GSH } & \multicolumn{2}{c}{ SERUM } & \multicolumn{2}{c}{ TISSUE } \\
\cline { 2 - 6 } & Mean \pm SD & P Value & Mean \pm SD & P Value \\
\hline \multirow{4}{*}{ Control } & $3.50 \pm 0.11$ & & $61.12 \pm 1.92$ & \\
& Control vs. EG & $1.62 \pm 0.04$ & $<0.0001 * * * *$ & $62.09 \pm 3.31$ & $>0.9999$ \\
& Control vs. EG+P50 & $2.64 \pm 0.83$ & $0.0005 * * *$ & $65.05 \pm 1.83$ & 0.5106 \\
& Control vs. EG + P100 & $1.57 \pm 0.04$ & $<0.0001 * * * *$ & $64.52 \pm 4.71$ & 0.7479 \\
& Control vs. EG + V & $1.60 \pm 0.02$ & $<0.0001 * * * *$ & $59.38 \pm 3.88$ & $>0.9999$ \\
& EG vs. EG+P50 & $2.639 \pm 0.83$ & $0.0002 * * *$ & $65.05 \pm 1.83$ & 0.7952 \\
& EG vs. EG + P100 & $1.571 \pm 0.04$ & $>0.9999$ & $64.52 \pm 4.71$ & $>0.9999$ \\
& EG vs. EG + V & $1.6 \pm 0.02$ & $>0.9999$ & $59.38 \pm 3.88$ & 0.9278 \\
& & & & & \\
\hline \multirow{4}{*}{28} & Control & $2.97 \pm 0.04$ & & $71.52 \pm 4.97$ & \\
& Control vs. EG & $1.47 \pm 0.02$ & $<0.0001 * * * *$ & $66.25 \pm 2.55$ & 0.1739 \\
& Control vs. EG+P50 & $1.93 \pm 0.77$ & $<0.0001 * * * *$ & $68.75 \pm 7.89$ & $>0.9999$ \\
& Control vs. EG + P100 & $1.49 \pm 0.03$ & $<0.0001 * * * *$ & $72.34 \pm 4.51$ & $>0.9999$ \\
& Control vs. EG + V & $1.43 \pm 0.02$ & $<0.0001 * * * *$ & $74.20 \pm 4.98$ & $>0.9999$ \\
& EG vs. EG+P50 & $1.928 \pm 0.76$ & 0.1657 & $68.75 \pm 7.89$ & $>0.9999$ \\
& EG vs. EG + P100 & $1.492 \pm 0.02$ & $>0.9999$ & $72.34 \pm 4.51$ & 0.0769 \\
& EG vs. EG + V & $1.433 \pm 0.02$ & $>0.9999$ & $74.2 \pm 4.98$ & 0.0129 \\
\hline
\end{tabular}

In our previous study [29], the efficiency of verapamil was shown on an urilithiasis rat model. In this study, we further evaluated the capability of propolis in comparison with Verapamil in a similar rat model. Considering these findings and previous data, both hyperoxaluria and $\mathrm{CaOx}$ crystal formation are certainly damaging to renal epithelial cells due to oxidative stress. Scavenging enzyme alterations adjust the T-AOC of the kidneys and crystal deposition signifying the high possibility of such specific changes due to the hyperoxaluria induced ischemic injury in renal tubular cells. Moreover, studies indicated that cellular injury noted in the renal papillary tubular epithelial cells due to hyperoxaluria-induced ischemia, might induce cell degradation, which could be at the bottom of the pathologic progression of urolithiasis. These findings confirm that during the hyperoxaluric phase some apoptotic events do take place in response to oxidative stress. Very limited crystallization was observed during the early phase in the affected kidneys as an incipient of crystal formation following hyperoxaluria. Furthermore, the verapamil and propolis applications were able to limit crystallization during late phase. Animals receiving Verapamil treatment demonstrated mildly limited oxalate crystal formation when compared with the EG only group, similar with the control group. During late phase, however, propolis was able to limit crystal formation significantly. Hereby, according to the microscopic evaluations while verapamil was capable of restricting crystal formation during late phase, propolis treatment was able to exhibit a better impact (Table 10, Figure 3). Furthermore, microscopically a far much lower stone formation and macroscopically softer and brighter kidneys with a color close to normal appearance were observed in the animals administered with propolis (data not shown).

Integrative and preventive therapies can possibly provide additional benefits to the modern treatment methods against urolithiasis. It is well known that developing an effective prophylactic approach to urolithiasis will promote the inhibition of new crystal formation. Many current models of calcium oxalate $(\mathrm{CaOx})$ stone disease suggest that the generation of ROS and subsequent lipid peroxidation is included in the tubular cell damage and apoptotic mechanism for stone formation. Typically, cells have various antioxidant systems to limit this molecular process, including enzymatic (SOD, CAT and glutathione peroxidase-GPx) and non-enzymatic (vitamins E, A and C) approaches. Thus, the oxidant/antioxidant balance is crucial for cell sensitivity against free-radical damage and an increased production of ROS in response to hyperoxaluria activates adaptive mechanisms in the kidney by up-regulating the antioxidant defense systems such as SOD, CAT and GSH. Moreover, 
recurrent idiopathic $\mathrm{CaOx}$ stone formers, with stones or simply crystals, were shown to concurrently have antioxidant deficiency [30].

Table 9. Estimation of serum and tissue levels of CAT within all groups

\begin{tabular}{clllll}
\hline \multirow{2}{*}{ Days } & \multicolumn{1}{c}{ CAT } & Mean \pm SD & P Value & Mean \pm SD & P Value \\
\hline \multirow{4}{*}{ Control } & $150.09 \pm 39.98$ & & $146.7 \pm 48.71$ & \\
& Control vs. EG & $131.30 \pm 15.18$ & 0.8114 & $135.6 \pm 10.12$ & $>0.9999$ \\
& Control vs. EG+P50 & $142.30 \pm 14.73$ & $>0.9999$ & $144.6 \pm 12.91$ & $>0.9999$ \\
& Control vs. EG + P100 & $119.80 \pm 19.70$ & 0.1728 & $118.8 \pm 11.58$ & 0.4037 \\
& Control vs. EG + V & $134.10 \pm 11.78$ & $>0.9999$ & $163.8 \pm 16.28$ & $>0.9999$ \\
& EG vs. EG+P50 & $142.3 \pm 14.73$ & $>0.9999$ & $144.6 \pm 12.91$ & $>0.9999$ \\
& EG vs. EG + P100 & $119.8 \pm 19.70$ & $>0.9999$ & $118.8 \pm 11.57$ & 0.5282 \\
& EG vs. EG + V & $134.1 \pm 11.78$ & $>0.9999$ & $163.8 \pm 16.27$ & 0.077 \\
& & & & $176.04 \pm 48.98$ & \\
& Control & $158.47 \pm 20.03$ & & & \\
& Control vs. EG & $142.00 \pm 18.94$ & $>0.9999$ & $231.40 \pm 28.14$ & $0.0066 * *$ \\
& & & & & 0.0003 \\
& Control vs. EG+P50 & $132.40 \pm 18.38$ & 0.3218 & $103.40 \pm 33.70$ & $* * *$ \\
& Control vs. EG + P100 & $184.30 \pm 47.57$ & 0.33 & $132.90 \pm 25.70$ & 0.0501 \\
& & & & 0.0002 \\
& Control vs. EG + V & $97.34 \pm 21.31$ & $0.0005 * * *$ & $101.80 \pm 17.21$ & $* * *$ \\
& EG vs. EG+P50 & $132.4 \pm 18.38$ & $>0.9999$ & $103.4 \pm 33.70$ & $<\mathbf{0 . 0 0 0 1 *}$ \\
& EG vs. EG + P100 & $184.3 \pm 47.57$ & $0.0097 * *$ & $132.9 \pm 25.70$ & $<\mathbf{0 . 0 0 0 1 *}$ \\
EG vs. EG + V & $97.34 \pm 21.30$ & $0.0061^{* *}$ & $101.8 \pm 17.21$ & $<\mathbf{0 . 0 0 0 1 *}$ \\
\hline
\end{tabular}

Many oxidative stress markers are increased in the experimental rat kidney models. For instance, MDA, a lipid peroxidation marker, is a commonly used oxidative stress marker although it can be found in fluctuating levels owing to dietary habits and lifestyle. Urinary 8-hydroxydeoxy guanosine (8-OHdG) levels, an indicator of oxidative damage on DNA, was elevated in patients with kidney stones and was related to tubular damage [31]. Studies conducted on tissue cultures displayed the influence of free radicals on intense inflammation and reproduction of numerous crystallization modulators. Renal cells secrete superoxide radicals in response to $\mathrm{CaOx}$ crystals, and antioxidants and free radical scavengers may conceivably eliminate the consequent cell damage. It has been shown that CAT and SOD, as free radical scavengers, prevented the damage induced by oxalate in vitro in animal kidney epithelial cell lines [32]. Furthermore, supplementary to the evaluation of the scavenging enzymes, total antioxidant capacity (T-AOC) is now commonly used in order to appraise the oxidant/antioxidant status. It was also considered as a favorable route to estimate the extent of oxidative stress $[33,34]$.

Elevated levels of oxidative stress have been reported in pathological states of the kidneys by numerous researchers [35]. Huang et al. demonstrated increased CAT and manganese superoxide dismutase (MnSOD) enzyme activities in rats with EG-induced early stage urolithiasis. All antioxidant enzyme activities were decreased aside from CAT on day 42 [17,36]. Increased ROS in vitro, and NO synthase (iNOS) and NFkB expressions in vivo indicate ascended oxidative stress in rat kidneys [32,37]. Furthermore, it has been shown that the Extracorporeal Shock Wave Lithotripsy (ESWL) treatment induces oxidative stress and reduces the antioxidant and trace element levels in rat kidneys [38]. In addition, renal tubular apoptosis have been associated with incremented ROS in rats [39]. Moreover, elevated renal ROS levels were also reported in obstructed kidneys in vivo along with the impairment of the prominent antioxidant enzymes, SOD, CAT and glutathione peroxidase (GPx) [40]. Various studies have been conducted on the favorable effect of the antioxidant and reactive oxygen scavenger agents against urinary obstruction [41], infection [42], and ischemia-reperfusion injury [43] induced renal damages. Following the observation of hyperoxaluric crystal deposition in the renal parenchyma and cellular injury in the tubular epithelium, preventive effect of the protective agents 
was investigated. Administration of antioxidants in hyperoxaluric rat models reduced renal injury, thus lipid peroxide production and $\mathrm{CaOx}$ crystal deposition in the kidneys indicated the involvement of ROS in hyperoxaluria-induced renal injury [44]. Calcium channel-blocking agents (CCB), antiinflammatory agents (as Tutukon ${ }^{\circledR}$ ) or vitamin E used as free radical scavenger agents were observed to restrict histologic changes and crystal deposition by minimizing free oxygen radical-induced alterations in parenchymatous organs [29,45-51]. In order to increase the blood flow to the affected organ, including kidneys, and regain the normal physiology, $\mathrm{CCB}$ agents are used to induce vasodilation and reduction of peripheral resistance, which is shown to successfully confine the ischemia-related alterations. Moreover, lemon juice has been proposed in the treatment of kidney stones due to its citrate and antioxidant content [52,53]. Citrate prevents crystal formation by inhibiting the saturation of calcium and the antioxidant content limits the renal tubular damage. Therefore, we suggest that elevated renal oxidative stress and the subsequent functional impairment of the endothelial cells may be the underlying inducer and/or initiator of urolithiasis development.

Among many fascinating features of propolis, there are protective effects such as antiinflammatory [54,55], xanthine oxidase (XOD) inhibitory and hypouricemic action [56-58], renoprotective, diuretic, antimicrobial, antioxidant and immunomodulator effects. Xanthine oxidase is an enzyme that generates reactive oxygen species and is further metabolized to uric acid [45]. A xanthine oxidase inhibitor, namely allopurinol, is known to inhibit the ischemia and reperfusion damage in many organs including kidneys and is also a component of the organ storage solution used for transplantations [59]. Flavonoids in propolis are extremely powerful antioxidants [60]. CAPE, an active compound of propolis, was investigated for lithium induced renal toxicity on rats and CAPE treatment was suggested to be protective [61] In addition, Holoch and Tracy observed a link between low serum antioxidant levels and incidences of kidney stones noted by the patients. There are studies that demonstrated the elimination of oxidative stress in kidneys to various degrees by propolis [62, 63]. Moreover, some flavonoids are effective in ameliorating blood pressure via escalating water and electrolyte excretion (as $\mathrm{Na}^{++}$reabsorption) from kidneys [64-67]. These mechanisms may have significance in stone formation.

Consequently, both visible crystal deposition and tubular injury due to oxidative stress might be confined by blood flow regulators (calcium antagonists) and antioxidant agents (propolis). Although verapamil is an efficient agent to prevent oxalate- induced AKI urolithiasis, it is a Ca channel blocker, thus it cannot be used for long durations since it will slow the heart rate and decrease the blood pressure of the patients. However, propolis treatment is non-toxic in appropriate usage and shown to be renal-protective with its high phenolic content and many properties beyond antioxidant. These findings suggest that propolis may be used to prevent stone formation in people prone to urolithiasis or for accidental EG induced renal injury.

Table 10. Comparative effects of ethylene glycol, verapamil and propolis on renal oxalate crystal deposition

\section{Administrated Agents}

\begin{tabular}{|c|c|c|c|}
\hline & $\begin{array}{l}\text { Ethylene glycol } \\
\qquad(\mathrm{n}=6)\end{array}$ & $\begin{array}{l}\text { Verapamil } \\
\qquad(\mathbf{n}=6)\end{array}$ & $\begin{array}{c}\text { Propolis } \\
(n=6)\end{array}$ \\
\hline $\begin{array}{r}\text { Oxalate crystal } \\
\text { deposition }(X \pm S E M)\end{array}$ & $13.67 \pm 0.88 *$ & $9.00 \pm 1.09 * *$ & $2.67 \pm 0.49 * * *$ \\
\hline
\end{tabular}


A

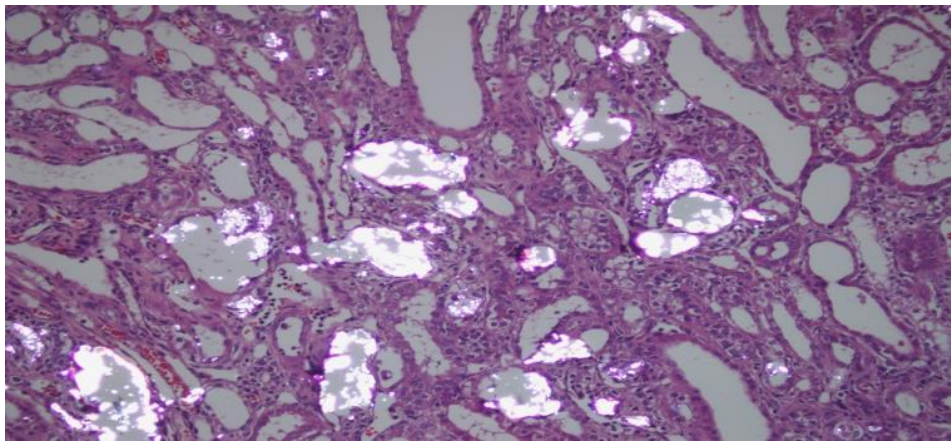

B

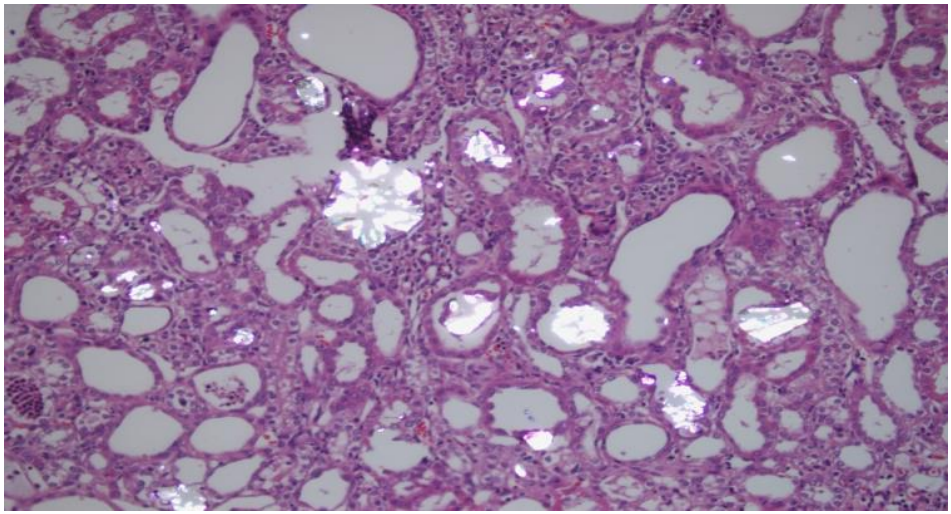

C

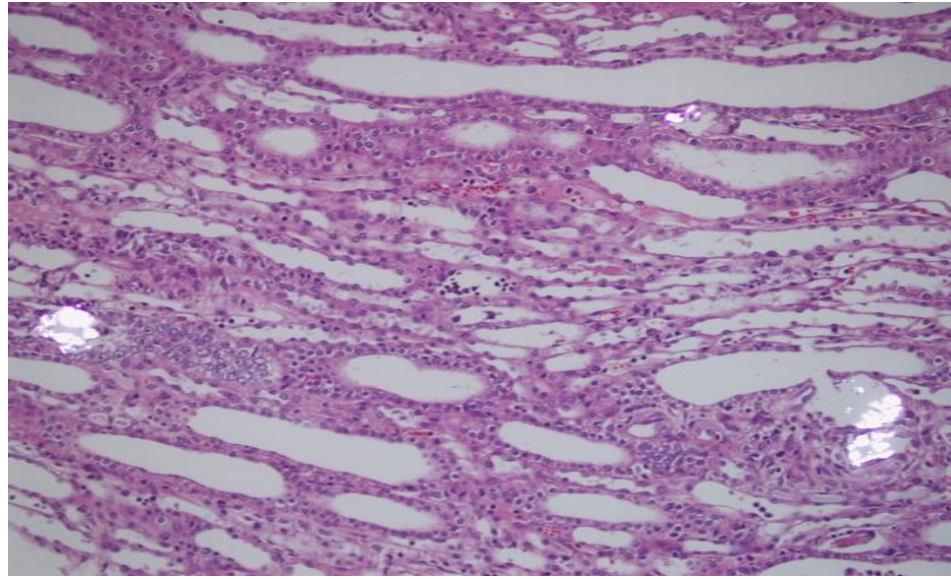

Figure 3. Evident crystal formation (EG group, dense deposition) in an animal undergoing hyperoxaluria induction (H\&E, Olympus polarizer filter, original magnification X200).

A: without any protective agent at late phase

B: with Verapamil application at late phase

C: with Propolis $50 \mathrm{mg} / \mathrm{kg}$ application at late phase

No metabolic evaluation was performed on rat urine, since the cages that were used were not suitable for urine sample collection in this study. Additionally, no assessments were made for quantitative histological analysis on the renal tissue samples. These aspects may be further evaluated in order to investigate the renal-related metabolic effects of propolis.

\section{Conclusions}

The presented findings deliver novel and substantial evidence on crystal-induced oxidative damage to the renal tissue, which provides a favorable environment for individual $\mathrm{CaOx}$ crystal attachment and subsequent development of kidney stones in vivo. Propolis treatment confined the $\mathrm{CaOx}$ crystal deposition in the kidney more than calcium channel blockers, via preventing the 
antioxidant imbalance in the tissues caused by hyperoxaluria. Moreover, many researchers now recognize a wide range of favorable impact of propolis. In this model, the predominant effect of propolis may be not only its antioxidant effect but also to anti-inflammatory, immunomodulatory and anti-ischemic activities owing to its high phenolic content (Table 2, supporting information S1). Therefore, propolis could be included to the prevention of hyperoxaluria-induced kidney stone formation. In this context, further studies should be carried out on their bioavailability, most appropriate preparations, and designating the safe and favorable doses to prevent or treat urolithiasis.

\section{Acknowledgements.}

The authors thank Altıparmak Inc., and Esra Çapanoğlu and Dilek Boyacıoğlu (Istanbul Technical University) for analyzing propolis samples and Helen Sue Eronat for her understanding and suggestions in English for the article. This study was funded by the Scientific Research Committee of Kartal Dr. Lutfi Kirdar Research and Training Hospital. The design of this study is a key part of a collaborative research process supported by Istanbul Development Agency (ISTKA/2010/KBO-62) and the Scientific Projects Coordination Unit of Istanbul University (27768)

\section{Informed consent}

Informed consent was not required (Experimental animal study). The authors have declared that no conflict of interest exists.

Ethical approval: Study approval was obtained from the Ethical committee of the Institute of Veterinary Control and Research, Pendik-İstanbul (94-14/013).

\section{Supporting Information}

Supporting information accompanies this paper on http://www.acgpubs.org/RNP

\section{ORCID}

Fehmi Narter: 0000-0003-2057-0142

Ayça Diren: 0000-0003-2033-3577

Alper Kafkasl1: 0000-0002-0362-8165

Allison P. Eronat: 0000-0002-8095-1759

M. Fatih Seyhan: 0000-0002-6218-0049

Hülya Y1lmaz-Aydoğan: 0000-0002-8837-6664

Sukran Sarıaya: 0000-0002-9093-3933

Seda Damla Hatipoğlu: 0000-0003-2674-1635

Kemal Sarica: 0000-0002-2473-1313

Oguz Ozturk: $\underline{0000-0002-2439-9269}$

\section{References}

[1] V. Bankova (2005). Recent trends and important developments in propolis research, Evid. Based Complement. Alternat. Med. 2(1), 29-32.

[2] H. Geckil, B. Ates, G. Durmaz, S. Erdogan and I. Yilmaz (2005). Antioxidant, free radical scavenging and metal chelating characteristics of propolis, Am. J. Biochem. Biotechnol. 1(1), 27-31.

[3] S.I. Falcao, C. Freire, A.C. Figueiredo and M. Vilas-Baos (2016). The volatile composition of Portuguese propolis towards its origin discrimination, Rec. Nat. Prod. 10(2), 176-188.

[4] M.C. Marcucci (1995). Propolis: Chemical composition, biological properties and therapeutic activity, Apidologie 26, 83-99.

[5] V.S. Bankova, S.L. De Castro and M.C Marcucci (2000). Propolis: Recent advances in research on chemistry and plant origin, Apidologie 31, 3-15. 
[6] B. Bueno-Silva, D. Kawamoto, E.S. Ando-Suguimoto, R.C.V. Casarin, S.M. Alencar, P.L. Rosalen and M.P.A. Mayer (2017). Brazilian red propolis effects on peritoneal macrophage activity: Nitric oxide, cell viability, pro-inflammatory cytokines and gene expression, J. Ethnopharmacol. 207, 100-107.

[7] A.M. Mahmoud and S.M. Abd El-Twab (2017). Caffeic acid phenethyl ester protects the brain against hexavalent chromium toxicity by enhancing endogenous antioxidants and modulating the JAK/STAT signaling pathway, Biomed. Pharmacother. 91, 303-311.

[8] F.L. Coe, A. P. Evan, E.M. Worcester and J.E. Lingeman (2010). Three pathways for human kidney stone formation, Urol. Res. 38(3), 147-160.

[9] R.L. Hackett, P.N. Shevock and S.R. Khan (1994). Madin-Darby canine kidney cells are injured by exposure to oxalate and to calcium oxalate crystals, Urol. Res. 22(4), 197-203.

[10] C.R. Scheid, H.K. Koul, L. Kennington, W.A. Hill, J. Luber-Narod, J. Jonassen, T. Honeyman and M. Menon (1995). Oxalate-induced damage to renal tubular cells, Scanning Microsc. 9(4), 1097-1105.

[11] S. Thamilselvan and S.R. Khan (1998). Oxalate and calcium oxalate crystals are injurious to renal epithelial cells: Results of in vivo and in vitro studies, J. Nephrol. 1, 66-69.

[12] S.R. Khan (1995). Calcium oxalate crystal interaction with renal tubular epithelium, mechanism of crystal adhesion and its impact on stone development, Urol. Res. 23(2), 71-79.

[13] M.H. Khaskhali, K.J. Byer and S.R. Khan (2009). The effect of calcium on calcium oxalate monohydrate crystal-induced renal epithelial injury, Urol. Res. 37(1), 1-6.

[14] J.C. Lieske, R. Norris, H. Swift and F.G Toback (1997). Adhesion, internalization and metabolism of calcium oxalate monohydrate crystals by renal epithelial cells, Kidney Int. 52(5), 1291-1301.

[15] H.K. Koul, S. Koul, S. Fu, V. Santosham, A. Seikhon and M. Menon (1999). Oxalate: From crystal formation to crystal retention, J. Am. Soc. Nephrol. 14, 417-421.

[16] M. Davalos, S. Konno, M. Eshghi and M. Choudhury (2010). Oxidative renal cell injury induced by calcium oxalate crystal and renoprotection with antioxidants: A possible role of oxidative stress in nephrolithiasis, J. Endourol. 24(3), 339-345.

[17] H.S. Huang, M.C. Ma, J. Chen and C.F. Chen (2002). Changes in the oxidant-antioxidant balance in the kidney of rats with nephrolithiasis induced by ethylene glycol, J. Urol. 167(6), 2584-2593.

[18] A. Meda, C.E. Lamien, M. Romito, J. Millogo and O.G. Nacoulma (2005). Determination of the total phenolic, flavonoid and proline contents in Burkina Fasan honey, as well as their radical scavenging activity, Food Chem. 91, 571-577.

[19] N.J. Miller and C.A. Rice-Evans (1997). Factors influencing the antioxidant activity determined by the ABTS + radical cation assay, Free Radical. Res. 26, 195-199.

[20] A. Kumaran and R. J. Karunakaran (2006). Antioxidant and free radical scavenging activity of an aqueous extract of Coleus aromaticus, Food Chem. 97, 109-114.

[21] I.F.F. Benzie and J.J. Strain (1996). The ferric reducing ability of plasma (FRAP) as a measure of 'antioxidant power': The FRAP assay, Anal. Biochem. 239, 70-76.

[22] R. Apak, K. Guclu, M. Ozyurek and S.E. Karademir (2004). Novel total antioxidant capacity index for dietary polyphenols and vitamins $\mathrm{C}$ and $\mathrm{E}$, using their cupric ion reducing capability in the presence of neocuproine: CUPRAC method, J. Agric. Food Chem. 52, 7970-7981.

[23] I. Gülçin, E. Bursal, M. H. Sehitoğlu, M. Bilsel and A.C. Gören (2010). Polyphenol contents and antioxidant activity of lyophilized aqueous extract of propolis from Erzurum, Turkey, Food Chem. Toxicol. 48(8-9), 2227-2238.

[24] X. Yang, H. Ding, Z. Qin, C. Zhang, S. Qi, H. Zhang, T. Yang, Z. He, K. Yang, E. Du, C. Liu, Y. Xu and Z. Zhang (2016). Metformin prevents renal stone formation through an antioxidant mechanism in vitro and in vivo, Oxid. Med. Cell. Longev. 2016, 4156075.

[25] F.A. Ghaeni, B. Amin, A.T. Hariri, N.T. Meybodi and H. Hosseinzadeh (2014). Antilithiatic effects of crocin on ethylene glycol-induced lithiasis in rats, Urolithiasis 42(6), 549-558.

[26] N. Zabaiou, A. Fouache, A. Trousson, S. Baron, A. Zellagui, M. Lahouel and J.A. Lobaccaro (2017). Biological properties of propolis extracts: Something new from an ancient product, Chem. Phys. Lipids. 207(Pt B), 214-222.

[27] M. Khoubnasabjafari, K. Ansarin and A. Jouyban (2015). Reliability of malondialdehyde as a biomarker of oxidative stress in psychological disorders, Bioimpacts 5(3), 123-127.

[28] Y. Itoh, T. Yasui, A. Okada, K. Tozawa, Y. Hayashi and K. Kohri (2005). Preventive effects of green tea on renal stone formation and the role of oxidative stress in nephrolithiasis, J. Urol. 173, 271-275.

[29] K. Sarica, A. Kafkasli, F. Narter, O. Ozturk, O. Yazici, B. Hamarat, C. Sahin and B. Eryildirim (2016). Hyperoxaluria-induced tubular ischemia: The effects of verapamil on the antioxidant capacity of the affected kidneys, Urolithiasis 44(6), 509-519.

[30] S.R. Khan (2014). Reactive oxygen species, inflammation and calcium oxalate nephrolithiasis, Transl. Androl. Urol. 3(3), 256-276. 
[31] C. Boonla, R. Wunsuwan, K. Tungsanga and P. Tosukhowong (2007). Urinary 8-hydroxydeoxyguanosine is elevated in patients with nephrolithiasis, Urol. Res. 35(4), 185-191.

[32] K. Aihara, K. J. Byer and S. R. Khan (2003). Calcium phosphate-induced renal epithelial injury and stone formation: Involvement of reactive oxygen species, Kidney Int. 64(4), 1283-1291.

[33] B. Palmieri and V. Sblendorio (2007). Oxidative stress tests: Overview on reliability and use. Part I, Eur. Rev. Med. Pharmacol. Sci. 11(5), 309-342.

[34] B. Palmieri and V. Sblendorio (2007). Oxidative stress tests: Overview on reliability and use. Part II, Eur. Rev. Med. Pharmacol. Sci. 11(6), 383-399.

[35] K. Ramaswamy and O. Shah (2014). Metabolic syndrome and nephrolithiasis, Transl. Androl. Urol. 3(3), 285-295.

[36] H.S. Huang, C.F. Chen, C.T. Chien and J. Chen (2000). Possible biphasic changes of free radicals in ethylene glycol induced nephrolithiasis in rats, BJU Int. 85(9), 1143-1149.

[37] M. Bas, V. Tugcu, E. Kemahli, E. Ozbek, M. Uhri, T. Altug and A.I. Tasci (2009). Curcumin prevents shock-wave lithotripsy-induced renal injury through inhibition of nuclear factor kappa-B and inducible nitric oxide synthase activity in rats, Urol. Res. 37(3), 159-164.

[38] I. Gecit, S. Kavak, I. Meral, N. Pirinçci, M. Güneş, H. Demir, N. Cengiz and K. Ceylan (2011). Effects of shock waves on oxidative stress, antioxidant enzyme and element levels in kidney of rats, Biol. Trace Elem. Res. 144(1-3), 1069-1076.

[39] C.H. Yeh, H.S. Chiang, T.Y. Lai and C.T. Chien (2011). Unilateral ureteral obstruction evokes renal tubular apoptosis via the enhanced oxidative stress and endoplasmic reticulum stress in the rat, Neurourol. Urodyn. 30(3), 472-479.

[40] T. Moriyama, N. Kawada, K. Nagatoya, M. Horio, E. Imai and M. Hori (2000). Oxidative stress in tubulointerstitial injury: Therapeutic potential of antioxidants towards interstitial fibrosis, Nephrol. Dial. Transplant. 15(6), 47-49.

[41] M. Zecher, C. Guichard, M. J. Velasquez, G. Figureueroa and R. Rodrigo (2009). Implications of oxidative stress in the pathophysiology of obstructive uropathy, Urol. Res. 37(1), 19-26.

[42] H.C. Han, S.H. Kim, S.H. Kang, O.R. Shin, H.K. Lee, H.J. Kim and Y.H. Cho (2007). Protective effects of cranberries on infection-induced oxidative renal damage in a rabbit model of vesico-ureteric reflux, BJU Int. 100(5), 1172-1175.

[43] A. Djamali (2007). Oxidative stress as a common pathway to chronic tubulointerstitial injury in kidney allografts, Am. J. Physiol. Renal. Physiol. 293(2), F445-455.

[44] P. Vanachayangkul, N. Chow, S. R. Khan and V. Butterweck (2011). Prevention of renal crystal deposition by an extract of Ammi visnaga L. and its constituent's khellin and visnagin in hyperoxaluric rats, Urol. Res. 39(3), 189-195.

[45] H. Sahin (2015). Honey as an apitherapic product: its inhibitory effect on urease and xanthine oxidase, $J$. Enzyme Inhib. Med. Chem. 31, 490-494.

[46] L. Benyi, Z. Weilherg and L. Puyun (1995). Protective effects of nifedipine and allopurinol on high energy shock wave induced acute changes of renal function, J. Urol. 153(Pt 1), 596-598.

[47] W.L. Strohmaier, A. Abelius, J. Billes, T. Grossmann, D.M. Wilbert and K.H. Bichler (1994). Verapamil limits shock wave-induced renal tubular damage in vivo, J. Endourol. 8(4), 269-273.

[48] H. Biri, H. S. Ozturk, S. Buyukkocak and M. Kacmaz (1998). Antioxidant defense potential of rabbit renal tissues after ESWL: protective effect of antioxidant vitamins, Nephron 79(2), 181-185.

[49] R. Selvam and M. Adhirai (1997). Vitamin E pretreatment prevents cyclosporine A-induced crystal deposition in hyperoxaluric rats, Nephron 75(1), 77-81.

[50] M.H. Parekh, R. Lobel, L. O’Connor, R.E. Leggett and R.M. Levin (2001). Protective effect of vitamin E on the response of the rabbit bladder to partial outlet obstruction, J. Urol. 166(1), 341-346.

[51] H.S. Huang, J. Chen, C.F. Chen and M.C. Ma (2006). Vitamin E attenuates crystal formation in rat kidneys: Roles of renal tubular cell death and crystallization inhibitors, Kidney Int. 70(4), 699-710.

[52] J.M. Zuckerman and D.G. Assimos (2009). Hypocitraturia: Pathophysiology and medical management, Rev. Urol. 11(3), 134-144.

[53] P. Tosukhowong, C. Yachantha, T. Sasivongsbhakdi, S. Ratchanon, S. Chaisawasdi, C. Boonla and K. Tungsanga (2008). Citraturic, alkalinizing and antioxidative effects of limeade-based regimen in nephrolithiasis patients, Urol. Res. 36(3-4), 149-155.

[54] S.R. Khan and D.J. Kok (2004). Modulators of urinary stone formation, Front. Biosci. 9, 1450-1482.

[55] M.T. Khayyal, M.A. El-Ghazaly and A.S. El-Khatib (1993). Mechanisms involved in the anti-inflammatory effect of propolis extract, Drugs Exp. Clin. Res. 19, 197-203.

[56] S.F. Mo, F. Zhou, Y.Z. Lv, Q.H. Hu, D.M. Zhang and L.D. Kong (2007). Hypouricemic action of selected flavonoids in mice: structure-activity relationships, Biol. Pharm. Bull. 30, 1551-1556.

[57] J. Sanhueza, J. Valdes, R. Campos, A. Garrido and A. Valenzuela (1992). Changes in the xanthine dehydrogenase/ xanthine oxidase ratio in the rat kidney subjected to ischemia-reperfusion stress: Preventive 
effect of some flavonoids, Res. Commun. Chem. Pathol. Pharmacol. 78(2), 211-218.

[58] J. P. Lavigne, X. Vitrac, L. Bernard, F. Bruyère and A. Sotto (2011). Propolis can potentialise the antiadhesion activity of proanthocyanidins on uropathogenic Escherichia coli in the prevention of recurrent urinary tract infections, BMC. Research. Notes. 29(4), 522. doi: 10.1186/1756-0500-4-522.

[59] P. Pacher, A. Nivorozhkin and C. Szabó (2006). Therapeutic effects of xanthine oxidase inhibitors: Renaissance half a century after the discovery of allopurinol, Pharmacol. Rev. 58(1), 87-114.

[60] D. Kolankaya, G. Selmanoglu, K. Sorkun and B. Salih (2002). Protective effects of Turkish propolis on alcohol-induced serum lipid changes and liver injury in male rats, Food Chem. 78(2), 213-217.

[61] F. Oktem, F. Ozguner, O. Sulak, S. Olgar, O. Akturk, H.R. Yilmaz and I. Altuntas (2005). Lithium-induced renal toxicity in rats: Protection by a novel antioxidant caffeic acid phenethyl ester, Mol. Cell Biochem. 277(1-2), 109-115.

[62] H. Ozyurt, M. K. Irmak, O. Akyol and S. Sogut (2001). Caffeic acid phenethyl ester changes the indices of oxidative stress in serum of rats with renal ischemia-reperfusion injury, Cell Biochem. Funct. 19(4), 259263.

[63] S. Ozen, O. Akyol, M. Iraz, S. Sogut, F. Ozugurlu, H. Ozyurt, E. Odaci and Z. Yildirim (2004). Role of caffeic acid phenethyl ester, an active component of propolis, against cisplatin induced nephrotoxicity in rats, J. Appl. Toxicol. 24(1), 27-35.

[64] Z. Wei, C. Minli, S. Qiyang, L. Yinghua and H. Fuliang (2011). Biological activities of Chinese propolis and Brazilian propolis on streptozotocin-induced type 1 Diabetes Mellitus in rats, Evid. Based. Complement. Alternat. Med. 2011, 468529.

[65] L. Borghi, T. Meschi, A. Guerra, A. Briganti, T. Schianchi, F. Allegri and A. Novarini (1999). Essential arterial hypertension and stone disease, Kidney Int. 55(6), 2397-2406.

[66] A. Wataru, N. Naomi, M. Hiroaki and M. Yoshinori (2004). Flavonoid-induced reduction of ENaC expression in the kidney of Dahl salt-sensitive hypertensive rat, Biochem. Biophys. Res. Commun. 315(4), 892-896.

[67] Y. Cao, S. Sagi, A. Hacker, A. Steidler, P. Alken and T. Knoll (2006). Impact of hypoxia and hypercapnia on calcium oxalate toxicity in renal epithelial and interstitial cells, Urol. Res. 34(4), 271-276.

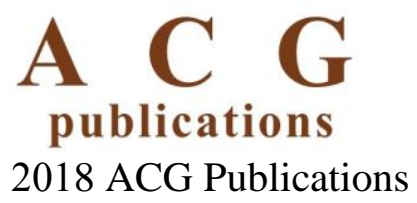

